\title{
Studying the Impact of Personality Constructs on Employees' Knowledge Sharing Behavior Through Considering the Mediating Role of Intelligent Competencies in Project-Oriented Organizations
}

\author{
Mehdi Abzari ${ }^{1}$, Arash Shahin ${ }^{2} \&$ Ali Abasaltian ${ }^{3}$ \\ ${ }^{1}$ Professor, Management Department, University of Isfahan, Isfahan, Iran \\ ${ }^{2}$ Associate Professor, Management Department, University of Isfahan, Isfahan, Iran \\ ${ }^{3}$ Ph.D. Candidate in Human Resource Management, Research Institute of ShakhesPajouh, Isfahan, Iran \\ Correspondence: Ali Abasaltian, Ph.D. Candidate in Human Resource Management, Research Institute of \\ ShakhesPajouh, Isfahan, Iran. E-mail: Abasaltian@yahoo.com
}

Received: March 1, 2015

Accepted: August 7, 2015

Online Published: January 16, 2016

doi:10.5539/mas.v10n6p194

URL: http://dx.doi.org/10.5539/mas.v10n6p194

The research is based on the Ph.D thesis.

\begin{abstract}
The impacts of individual factors on knowledge management actions as well as the impacts of psychological attributes on employees' knowledge sharing behavior are highly paid attention by many authors. Such attributes as dynamic environment, the expansion of organizational complexities, generating mass information and knowledge-orientation of project-oriented organizations have caused that focus on knowledge is extraordinarily increased in organizations.

In many scientific documents, the then impacts by psychological traits on knowledge sharing behavior are expressed. Personality is seen as the most important predictor component of human behavior. Current paper studied the impact by employee's personality constructs on their knowledge sharing behavior by considering the role of individuals' intelligent competencies. Present study is a survey - type with descriptive approach. Its sample size was 118 scholars, employees and managers in project - oriented organizations while research data collection tool was an 80-item questionnaire. Its reliability was calculated by Chronbach's alpha ratio while its content validity was determined by connoisseurs. PLS software package is used to test research hypotheses. Measuring the personality constructs is based on Five - Big Model (NEO) while measuring intelligent competencies is adapted to Boaytzs model. Data analysis shows the direct impact by personality constructs on knowledge sharing behavior while it does not support the mediating role by intelligent competencies in this regard.
\end{abstract}

Keywords: personality constructs, knowledge sharing behavior, intelligent competencies, project - oriented organizations

\section{Introduction}

Knowledge management has become a critical area in management during recent decade. In today global economy, organizations in general and project - oriented organizations in particular will not be able to guarantee their future without right knowledge management. Knowledge is recognized as the highest mood of information (Kebede, 2010). Knowledge can create competitive advantage for organization (Politis, 2001; Birasnav et al, 2011). Researchers have discussed on different aspects of knowledge management both theoretically and practically. However, knowledge management still needs growth and development. Knowledge sharing is also defined as giving and taking knowledge (Bircham et al, 2005; McDermott and O'Dell, 2001).

Concerning information mass production, workplace dynamism, temporary nature, uniqueness, unpredictability and non-repetitiveness of project - oriented organizations' activities, the importance of knowledge sharing is unavoidable in organizations. Project - oriented organizations are those ones that do their most activities through projects and have more focus on project aspects than operational aspects in organizational processes (Lindquist, 2004). The velocity of transferring and changing the information is so high that it was not imaginable before 
(Crawford, 2005). In a knowledge - oriented economy, organizational intangible assets including employees' know - how are seen as their competitive advantages (Nahapiet and Ghoshal, 2998). If organizations do not consider the vital and influential role of information, they would lose their competitiveness and strategic advantages against rivals. According to scientific resources, the most important affecting factors on employees' knowledge sharing behavior are their personal and psychological traits. Hence, intelligent competencies and personality constructs are studied in this research has the most important predictors of human behavior.

Knowledge is not a physical material. Hence, psychological traits, personality, will, motivation and emotional intelligence play a very vital role in knowledge sharing (Jafari et al, 2012) while other personal aspects of knowledge management are neglected (Martin, 2009). Generally, intelligence and personality are studied to predict to conceive the behavior better. Knowledge sharing is performed through face - to - face interactions and collective communications in organizations (Cross et al, 2001) while past researches had mainly focused on technical aspects of knowledge sharing (Davenport et al, 1998). Knowledge sharing is vital for organizations (Hsu, 2008; Huang, 2009) since it enables them to develop skills and competencies, values and to continue competitive advantages (Wang and Noe, 2010; Ji et al, 2009).

Various researches have emphasized on the prerequisite of the expansion of knowledge sharing behavior in developing products, services and modern technologies (Renzl, 2008). It has caused that knowledge sharing becomes as one of the most current issues in both individual and organizational levels in all managerial branches (Hoff et al, 2009). Present study attempts to clarify dark parts of knowledge sharing behavior. The main aim of the research is to illustrate the role of individuals' constructs on $v$ sharing behavior through considering the mediating role of intelligent competencies.

\section{Literature Review}

\subsection{Knowledge Sharing Behavior}

Knowledge sharing is voluntarily dissemination of acquired skills and experience (La and Van Gui, 2008). Put it differently, knowledge sharing is defined as initiatives by which people disseminate some information among others (Farterl and Seryao Stava, 2002). Lee (2001) believes that knowledge sharing includes knowledge transfer and distribution (explicit and tacit knowledge) from one person, group or organization to others. Knowledge sharing is the most part of knowledge management. The tools by which knowledge is shared and the factors that facilitate knowledge sharing and transfer are, inter alia, the radical issues in knowledge management (Renzl, 2008). Knowledge sharing among employees and inside groups allows organizations to use knowledge - based resources and convert it into capital (Cabriera and Cabriera, 2002; Wong and Noy, 2010). Knowledge sharing as people's contribution in collective investment is an important issue which helps the organization to expand the best ways of performing the tasks and learning and mitigate their test and errors (Namijai et al, 2007).

Davenport believes that knowledge sharing among employees means to make it accessible for others in the organization. It is a process by which knowledge is concerted into an understandable and usable way for others. Also, Davenport points that knowledge is voluntarily and it is in turn to distinguish reporting business trend based on common policies in the organization. Knowledge sharing involves deliberated acts by people who contribute in knowledge exchanges activities and are not forced to do that. Authors in management arena believe that $\mathrm{v}$ sharing is more on adaptability to social dynamics in workplace than technology. These people are more emphasizing on building knowledge sharing in the organization (Davenport and Pursak, 1998).

Many authors agree that personal knowledge is effective in growing general knowledge of the organization and effectiveness in knowledge - oriented works are depended to new knowledge generation directly and sharing profitable knowledge through interaction between tacit and explicit knowledge (Spender, 1996).

Knowledge sharing is important for organizations and companies since it enables them to expand their skills and competencies in order to achieve a sustainable competitive value. Besides, when people share their personal knowledge or integrate it with others', then innovation emerges (Matzler et al, 2006).

\subsection{Intelligent Competencies}

Cognitive intelligence, social intelligence and emotional intelligence are three sides of human mind triangle. Although no model for intelligence competencies was found in studying research background and scientific articles, its components can be enounced as below:

Emotional intelligence competency shows the ability to understand and utilize emotional information of other people (Boyats \& Raoti, 2009). Social intelligence competency is the ability to interact with other people and attract their cooperation. It also shows successful links with others (Boyats et al, 2009). This competency shows the ability of thinking and analyzing situationa and information which yield into more excellent and efficient 
performance (Boyats and Goleman, 2001; Ramo et al, 2009).

According to Boyats, the components of intelligence competency are expressed as below:

\section{Emotional intelligence}

- Self - awareness: it includes the recognition of priorities, internal states and emotional self - awareness.

- Self - management: it shows the management of internal states and the ability of emotional renewal upon a social hurt, the ability on action not reaction, stability in behavior, feeling of responsibility in work, resilience against changes and welcoming new theories.

\section{Social intelligence competency}

- Social awareness: it shows awareness of emotions, needs and concerns of others.

- Empathy: it points out the recognition of others' emotions. Social understanding means to conceive different dimensions of others' feelings and a proper reaction toward our surrounding people. It shows the sense of responsibility for other people.

- Management relations: it includes such elements as coaching, aspiring leadership, penetration, conflict management and team working.

\section{Cognitive intelligence competency}

- Systemic thinking: it shows the ability to see a situation and its reasons and to conceive information flow in the organization.

- Model recognition: the ability to see apparent random issues in the format of a model (Boyats, 2009).

\subsection{Personality Constructs}

Personality studies in past years are highly paid attention and such study focus will be continued (Trouba, 2007). A mode which has attracted the highest attention and support is five factors model (Simms, 2009). Studies indicate that five big has a genetic basis (Digman, 1990) and can be highly inherited (Jang, Livesley and Vernon, 1996) and remains fix properly overtime (Costa and McCra, 1992). Five big aspects can be extended to all cultures (Salgado, 1997). Since these factors are provided generally, many researches support them (Costa et al, 1999; McAdams, 2001 cited by Cobb, 2007; McGraw and Costa, 1987).

The model of Five Big is one of the newest and widely applied personality model so that some researchers of personality believe that it is represents the best conceptualization of personality (Goldberg, 1990). Authors believe that an individual's personality profile would show predictions on his/her behavior in all situations (Robertson and Colinan, 1998). According to this model, Personality Five Big include: neurosis, extraversion, flexibility, agreeableness and responsibility. Neurosis is the distance between emotional stability and instability. People with such personality traits tend to anxiety, insecurity feeling, shamefulness and upset behaviors (McGraw and Costa, 1987). They are less successful in their interpersonal interactions (McAdams, 2006). Extravert people are seen as active people (Burknov and Standorv, 2008; Schton, 2006). In scientific studies, it is pointed out that extraversion associates positively with contributive behavior (Lipine and Dean, 2001). People with lower scores in this trait like to be in shadow and to talk less (Miglier, 2011) while people with higher scores are flexible, intellectual and imaginative (Goldberg, 1990). They are interested in changing their life and looking for new knowledge (Ricky, 1994). Agreeableness points out how to interact with others (Burknov and Standorv, 2008). People with higher score in agreeableness are trustable, kind and strong (Wulf and Kim, 2012). Lipine and Dean (2001) assert that agreeableness has a positive and significant relationship with contributive behaviors. Responsibility shows such traits as preciseness, organized and planned and relates to job and educational progresses (Rice, 2007). It includes such traits as hardworking, progress - orientation and perseverance. These people are trustable, ambitious, energetic, predictable and willful (Cobb, 2007).

\subsection{Project-Oriented Organizations}

These are matrix organizations by flexible and flat structures and are based on teams and projects (Engsbo, 2007). Project team members do not expect to work with each other again and they have not already work with each other (Ajmal and Caskenin, 2008). Project - oriented organizations are called as knowledge or learning organizations. Due to their need to business stability in market competitive environment, traditional organizations have tended toward project orientation (England et al, 2008). Since in project - oriented organizations, the numbers and types of projects are constantly changing, these organizations have dynamic and changing borders (Bayer et al, 2006). Usually, generated knowledge from past projects are documented and stocked in people's minds. Employees allotted generated knowledge in past projects to similar current projects. 
This knowledge can be shared to improve project implementation. Knowledge management helps employees in project-oriented organizations to achieve nedded information to make better decisions in order to save the usage of resources (Cassoy and Hilikary, 2003).

Innovation promotion, standardization, avoid reworking, mitigating the errors, customer satisfaction, improving service quality and allocating resources optimistically are, inter alia, the aims of knowledge management in project - oriented organizations (Hanish et al, 2009; Tang and Nenmien, 2009; Singley and Anderson, 1989). Studies indicate that systematic transfer of knowledge has a remarkable impact on project success. In other words, creating a climate to facilitate knowledge exchange and the mechanism of effective knowledge mechanism increases team members' capability to improve project success. Knowledge transfer in a project may be occurred in different levels including interpersonal, from people to groups, inter-groups and intra-groups (Carlsen and Gotshalk, 2004).

\section{Research Background}

The models by Vah et al (2007) and Yun and Allyn (2005) show giving importance to organization and receiving awards. To this end, Von Krogh (2003) asserts that giving importance to organization is a social norm in human relations, in this line, Makino and Inkpen (2003) express that social capital and knowledge sharing in two ways. First, social capital creates a set of regular organizing as the knowledge coding mechanism jointly to foster organizational identity. Second, social capital improves the efficiency of sender and receiver reactions and it mitigates the possibility of opportunistic behaviors and the necessity of costly processes and exchange costs. In knowledge sharing climate, Davenport et al, (1998) assert that job knowledge is constrained by man nature. According to Eraly and Pondy, there is a positive relationship between the possibility that actors conduct information toward others and the awards people expect from knowledge sharing. In their research on knowledge sharing, Kohenkgul et al, (2007) studied different factors such organizational culture, commitment, organizational climate, job satisfaction, structure promotion and power feeling. In his article, Yeng (2012) studied the role of leadership and organizational culture through organizational learning on knowledge sharing among the faculties of Malaysian universities. Studies by Renzel (2008) emphasize on mitigating the fear of losing unique values due to trust in management. Lin (2007) studied affecting factors on knowledge sharing in organizations. He studied there below factors:

Organizational structure attributes: This research has investigated three traits: formality, focus and complexity. Organizational culture: He defined organizational culture as the common belief, shared values and tangible laws among all organizational members.

Inter-unit interactions: trust and commitment are the main parts of interaction success inside the organizations.

Researches indicate that the most important barrier in effective knowledge management in the organization is the lack of knowledge sharing culture and not understanding its advantages among employees. As a result, organizational culture is regarded as one of the most affecting factors on successful dissemination and acceptance of knowledge management systems. One can introduce a new technology as a cultural change issue (Schien, 1989). Chong (2005) asserted that knowledge management activities in developing human force capacity for interactions based on creative ideas generation and knowledge toward affecting innovations. A study by Lee (2007) show that knowledge base of an organization is increasingly considered as a radical and infrastructural factor of performance. A study by Delang and Fehi (2000) show that trust between an organization and its departments and organizational members impacts positively on information flow in the organization and, as a result, it would increase the volume of shared knowledge. Probst et al (2000) assert that there are three barriers for knowledge sharing including people's anxiety on the fact that knowledge sharing would lead into their job security mitigation, unawareness of knowledge owners on the fact that his knowledge is profitable for others and the lack of enough time for knowledge sharing. As previous researches show, people's psychological traits are, inter alia, affecting factors on knowledge sharing less investigated by authors. Intelligence and personality are two important psychological factors in predicting human behaviors. By assuming the equal concept of knowledge sharing and knowledge sharing behavior, present paper has studied personality constructs and intelligence competencies.

\section{Methodology}

This is a descriptive type study. Since a systemic set of data is gathered by a questionnaire, it is a survey. The questionnaires were distributed and gathered among the members of research population in three projectoriented organizations both personally and electronically. Research population (130) consisted experts, deputies or supervisors of these organizations. Data collection was conducted in spring 2014. 118 questionnaires were completed and returned. So, response rate was $90 \%$. The questionnaire consists of four parts. The first part 
included demographical questions, the second part included intelligence competency questions, the third part consisted on personality constructs questions and the final part included questions on measuring knowledge sharing behavior. The reliability and validity of intelligence competencies are proved in past researches (Hajj Karimi, 2012). This questionnaire measures three aspects: emotional intelligence competencies, social intelligence competencies and cognitive intelligence competencies. The reliability and validity of knowledge sharing questionnaire is also proved by scientific reputable articles. This questionnaire measures employees' knowledge sharing behavior (Tseng, 2011). Measuring personality constructs is concluded by Neo questionnaire and its validity and reliability is conducted in various researches. This questionnaire measures the Five Big (neurosis, extraversion, flexibility, agreeableness and responsibility) (Savsier, 1998; Fernheim, 1997). To determine the overall validity of questionnaire, elites' opinions are used and confirmed upon minor modifications. To measure total reliability, Chronbach's alpha value (0.83) is used.

\section{Analysis}

5.1 Studying the Relationship Between Intelligence Competencies and Personality Constructs with Knowledge Sharing Behavior

Major hypothesis 1: Personality constructs impact on people's knowledge sharing behavior in project - oriented organizations.

Major hypothesis 2: Intelligence competencies impact on people' knowledge sharing behavior in project oriented organizations.

Table 1 is the summary of PLS analysis to test the main model especially standardized path ratio $(\beta)$ and statistical T. Below; all hypotheses are analyzed in brief. Beta ratio value shows that the impact rate of personality constructs on knowledge sharing behavior is $79 \%$ namely $79 \%$ of changes in knowledge sharing behavior are due to personality constructs; since computed t value is greater than 1.96 , one can say that there is a positive and significant relationship between personality constructs and knowledge sharing behavior in project oriented organizations.

Beta value is 0.032 for the second major hypothesis; since computed t value is lesser than 1.96 , one can say that intelligence competencies have no impact on knowledge sharing behavior in project - oriented organizations.

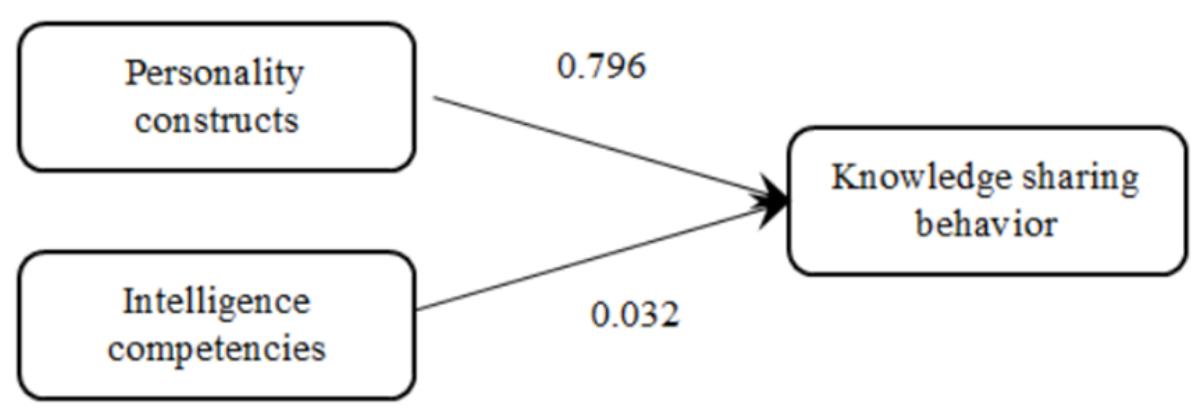

Figure 1. Research tested mode (path ratio)

Table 1. Results of model test

\begin{tabular}{ccccccc}
\hline Test result & $\mathrm{T}$ & Standard error & SD & Path ratio & \multicolumn{2}{c}{ Hypotheses } \\
& & & & & Dependent variable & Independent variable \\
\hline Supported & 18.05 & 0.04 & 0.04 & 0.796 & Knowledge sharing behavior & Personality constructs \\
Not supported & 0.52 & 0.06 & 0.06 & 0.032 & Knowledge sharing behavior & Intelligence competencies \\
\hline
\end{tabular}

Since the hypotheses regarding the impact by intelligence competencies on knowledge sharing behavior was not supported, it is investigated here whether intelligence competencies can mitigate the relationship between personality constructs and knowledge sharing behavior or not. In other words, how is the relationship between personality constructs and knowledge sharing behavior among people with lower and higher levels of intelligence competencies? The relevant model is: 


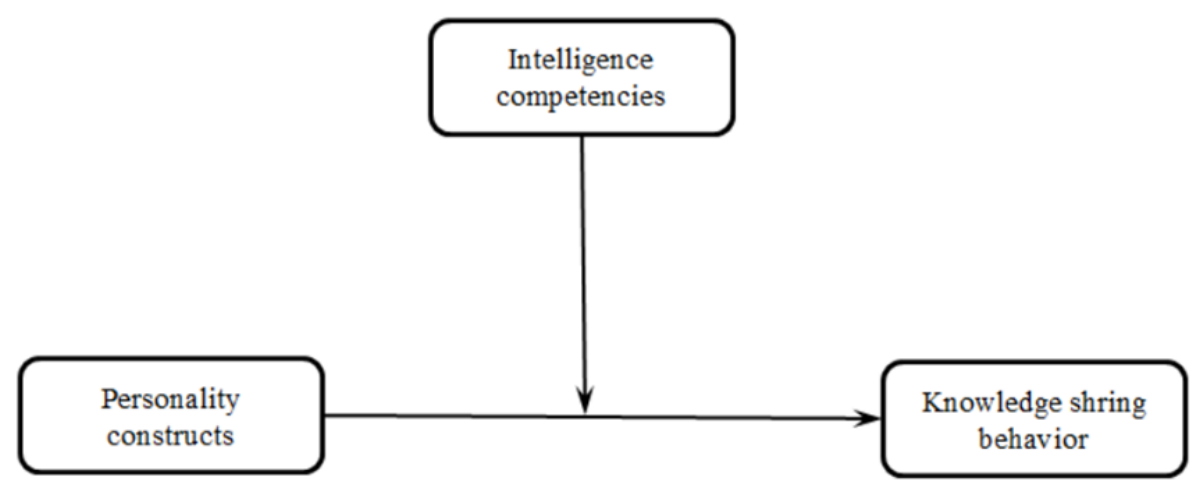

Figure 2. research model by the mediating role of intelligence competencies

To test the model, subjects were divided into two groups. The first group had lower while the second group had higher intelligence competencies. Noteworthy, the cutoff point is the people with average intelligence competencies (3.25). Below, the model is tested in two groups.

Personality
constructs $\quad$\begin{tabular}{c}
$\beta=0.567$ \\
\cline { 2 - 2 }$=14.793$
\end{tabular}

Figure 3. people in lower levels of intelligence competencies

As mentioned in major model section, it is initially necessary to determine the reliability of studied construct to show if selected questions enjoy necessary precise for measuring the respective constructs. Upon model test and needed modifications in terms of properness of indicators, factor load for each question is shown in table 2 .

Table 2. Factor loads of indicators in the model of people with lower levels of intelligence competencies

\begin{tabular}{|c|c|c|c|}
\hline Mixed reliability & AVA & Factor load & Items \\
\hline \multirow[t]{10}{*}{0.90} & 0.49 & 0.63 & Personality type 1 \\
\hline & & 0.65 & Personality type 2 \\
\hline & & 0.74 & Personality type 3 \\
\hline & & 0.65 & Personality type 4 \\
\hline & & 0.69 & Personality type 5 \\
\hline & & 0.79 & Personality type 6 \\
\hline & & 0.66 & Personality type 7 \\
\hline & & 0.69 & Personality type 8 \\
\hline & & 0.79 & Personality type 9 \\
\hline & & 0.65 & Personality type 10 \\
\hline \multirow[t]{3}{*}{0.80} & 0.58 & 0.62 & Knowledge sharing 1 \\
\hline & & 0.79 & Knowledge sharing 2 \\
\hline & & 0.85 & Knowledge sharing 3 \\
\hline
\end{tabular}


Mixed validity and AVE are two other indicators for internal consistency of constructs explained in previous sections. These indicators are expressed in table 2 . Therefore, constructs mostly enjoy proper mixed reliability. To study the validity of constructs, periodical item loads are used and the results are rendered in table 3 .

Table 3. the results of periodical item loads in the model of people with lower intelligence competencies

\begin{tabular}{lll}
\hline Knowledge sharing behavior & Personality constructs & Items \\
\hline 0.48 & 0.63 & Personality Type 1 \\
0.40 & 0.65 & Personality Type 2 \\
0.39 & 0.74 & Personality Type 3 \\
0.39 & 0.65 & Personality Type 4 \\
0.48 & 0.69 & Personality Type 5 \\
0.51 & 0.79 & Personality Type 6 \\
0.45 & 0.66 & Personality Type 7 \\
0.59 & 0.69 & Personality Type 8 \\
0.57 & 0.79 & Personality Type 9 \\
0.33 & 0.65 & Personality Type 10 \\
0.62 & 0.37 & Knowledge sharing 1 \\
0.79 & 0.55 & Knowledge sharing 2 \\
0.85 & 0.59 & Knowledge sharing 3 \\
\hline
\end{tabular}

As seen in above table, items enjoy proper validity. Studying the reliability and validity of the second model:

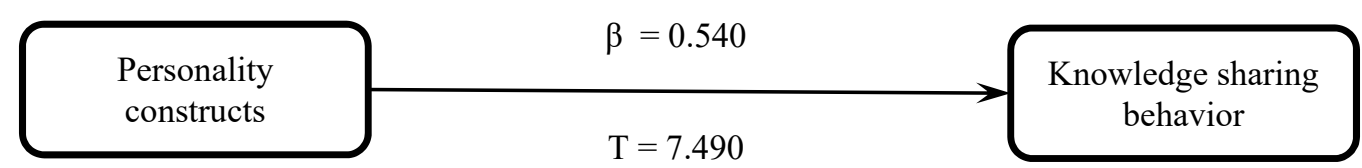

Figure 4. people with higher levels of intelligence competencies

Factor load values and fitness indicators for above model as well as their acceptance measures are mentioned in below tables. As seen, factors loads are in proper level upon modifying the model.

Table 4. Factor loads of indicators in the model of people with higher intelligence competencies

\begin{tabular}{|c|c|c|c|}
\hline Mixed reliability & AVA & Factor load & Items \\
\hline \multirow[t]{7}{*}{0.91} & 0.50 & 0.66 & Personality Type 1 \\
\hline & & 0.74 & Personality Type 1 \\
\hline & & 0.71 & Personality Type 1 \\
\hline & & 0.75 & Personality Type 1 \\
\hline & & 0.70 & Personality Type 1 \\
\hline & & 0.66 & Personality Type 1 \\
\hline & & 0.75 & Personality Type 1 \\
\hline
\end{tabular}




\begin{tabular}{|c|c|c|c|}
\hline & & 0.74 & Personality Type 1 \\
\hline & & 0.61 & Personality Type 1 \\
\hline & & 0.71 & Personality Type 1 \\
\hline \multirow[t]{3}{*}{0.77} & 0.54 & 0.83 & Knowledge sharing 1 \\
\hline & & 0.67 & Knowledge sharing 1 \\
\hline & & 0.68 & Knowledge sharing 1 \\
\hline
\end{tabular}

In figure 5, average values, AVE and mixed reliability of such variables are mentioned. Therefore, constructs enjoy proper mixed reliability.

Table 5. The results of items periodical loads in the model of people with higher levels of intelligence competencies

\begin{tabular}{ccc}
\hline Knowledge sharing behavior Personality constructs & Items \\
\hline 0.39 & 0.66 & Personality Type 1 \\
0.59 & 0.74 & Personality Type 2 \\
0.34 & 0.71 & Personality Type 3 \\
0.41 & 0.75 & Personality Type 4 \\
0.26 & 0.70 & Personality Type 5 \\
0.28 & 0.66 & Personality Type 6 \\
0.43 & 0.75 & Personality Type 7 \\
0.29 & 0.74 & Personality Type 8 \\
0.24 & 0.61 & Personality Type 9 \\
0.31 & 0.71 & Personality Type 10 \\
0.83 & 0.50 & Knowledge sharing 1 \\
0.67 & 0.31 & Knowledge sharing 2 \\
0.68 & 0.31 & Knowledge sharing 3 \\
\hline
\end{tabular}

To study the validity of constructs, items periodical loads are used. The results are in proper levels and shown in table 1. Below, the significance difference of Beta for two models to determine the mediating role of intelligence competencies is investigated.

Table 6. Total fitness indicators of two models

\begin{tabular}{|c|c|c|c|}
\hline Model 2 & Model 1 & Hypothesis test & \\
\hline Supported & Supported & $\begin{array}{l}\text { Personality constructs impact on knowledge sharing behavior in } \\
\text { project - oriented organizations. }\end{array}$ & $\begin{array}{c}\text { Sub } \\
\text { hypothesis }\end{array}$ \\
\hline 0.540 & 0.675 & & Beta \\
\hline 0.072 & 0.046 & & $\begin{array}{l}\text { Standard } \\
\text { Error }\end{array}$ \\
\hline 7.490 & 14.79 & & $\mathrm{~T}$ \\
\hline 0.291 & 0.456 & & $\mathrm{R}^{2}$ \\
\hline
\end{tabular}

Concerning table 6, both models enjoy proper fitness. Therefore, they can be compared. Concerning different Beta for both models, below equation is used to determine their significance. If $\mathrm{T}$ is greater than 1.96, such difference is significant; otherwise it is not significant. 


$$
\begin{gathered}
t=\frac{\text { Path }_{\text {Sample } 1_{-1}-\text { Path }_{\text {Sample }_{-2}}}}{\sqrt{\mathrm{SE}_{\text {Sample }_{-1}}^{2}+\mathrm{SE}_{\text {Sample }_{-2}}^{2}}} \\
t=\frac{0 / 67-0 / 54}{\sqrt{0 / 46^{2}+0 / 072^{2}}}=1 / 548
\end{gathered}
$$

Computed $\mathrm{T}$ value $(\mathrm{T}=1.548)$ indicates that Beta difference is not significant for both models. Therefore, intelligence competencies cannot mitigate the relationship between personality constructs and knowledge sharing behavior. In other words, intelligence competencies play no mitigating role in the relationship between personality constructs and knowledge sharing behavior.

\section{Conclusion}

Efforts on expanding knowledge and knowledge management are considered as the most important organizational capitals. Project - oriented organizations operate in dynamic, unique, temporary environment involved with technological complexities. Such attributes have caused the generation of huge volume of knowledge and information in these organizations.

Project - oriented organizations should enjoy the capabilities to identify, acquire, utilize and share knowledge in order to move toward knowledge orientation. Since knowledge sharing behavior has a special association with people's psychological traits, it is attempted in present paper to use two personality construct and intelligence competency components.

Research findings do not support the impact by intelligence competencies on employees' knowledge sharing behavior while they determine the impact by people's personality constructs on knowledge sharing behavior. Following to conducted analyses, it is tried to study the mediating role of intelligence competencies while this hypotheses is not supported by research findings.

Future researches can study the issue in other organizations with different behaviors and attitudes and to study the relations between other psychological components such as mental pathology variables (distrust, social withdrawal, shame, social displeasure, depression, stress and philanthropy) by different methods like modeling and fuzzy techniques.

\section{References}

Ajmal, M., \& Koskinen, K. (2008). Knowledge Transfer in Project-Based Organizations: An Organizational Culture Perspective. Project Management Journal, 39(1), 7-15.

Bartol, K., \& Sirvastave. A. (2002). Encouraging knowledge sharing: the role of organizational reward system. Journal of Leadership \& Organization Studies, 9(9), 64-76.

Bayer, S., \& Gann, D. (2006). Innovation and the Dynamics of Capability: Accumulation in Project-Based Organization, Imperial College London, South Kensington Campus, London.

Birasnav, M., Rangnekar, S. \& Dalpati, A. (2011). Transformational leadership and human capital benefits: The role of knowledge management. The Leadership \& Organization Development Journal, 32(2), 106-126.

Bircham-Connolly, H., Corner, J., \& Bowden, S. (2005). An Empirical Study of the Impact of Question Structure on Recipient Attitude during Knowledge Sharing. The Electronic Journal of Knowledge Management.

Cabrera, A., \& Cabrera, E. F. (2002). Knowledge Sharing Dilemmas. Organizational Studies, 23(5), 687-710.

Crawford, C. B. (2005). Effects of transformational leadership and organizational position on knowledge management. Journal of Knowledge Management, 9(6), 6-16.

Cross, R., Parker, A., Pursak, L., \& Borgatti, S. P. (2001). Knowing what we Know: Supporting Knowledge Creation and Sharing in Social Network. Journal of Organizational Dynamicss, 30(2), 100-120.

Davenport, T. H., \& Prusak, L. (1998). Working Knowledge: How Organization Manage What They Know, Boston: Harvard Business School Press.

Davenport, T. H., De Long, D. W., \& Beer, M. C. (1998). Succesful Knowledge Management Projects”, Sloan Management Review, 30(2). 43-56.

Englund, R., Rand, C., \& Sloane, J. (2008). Achieving a Project-Based Organization Culture, Madeline learning presents. Retrieved from http://www.madlinelearning.com 
Engsbo, M., \& Sandhu, M. (2007). Emerging E-Communication Technologies and Their Usage in Project-Based Organizations. Swedish School of Economics and Business Administration, Management, 2(4).

Furnham, A. F. (1997). Knowing and faking one's Five-Factor personality score. Journal of Personality Assessment, 69(1), 229-243 .

Hanisch, B., Linder, F., Mueller, A., \& Wald, A. (2009). Knowledge management in project environment. Journal of knowledge management, 13(4), 148-160.

Hooff, B., \& Husman, M. (2009). Managing knowledge sharing: Emergent and engineering approaches. Information and Management, 46, 1-8.

Hsu, C. (2008). Knowledge sharing practices as a facilitating factor for improving organizational performance though human capital: Preliminary test. Export Systems with Applications, 35, 1316-1326.

Huang, Ch. (2009). Knowledge sharing and group cohesiveness on performance: an empirical study of technology R\&D teams in Taiwan. Technovation, 29, 786-797.

Jafari, M., Akhavan, P., Hosnavi, R., \& Abasaltian, A. (2013). A Study of the Relationship between Psychological Traits of Individuals with Aspects of Personal Knowledge management. Journal of research in human resources management, 4(2), 1-21.

Ji, M., Hung, J., Chen, S., \& Jou, C. (2009). Fostering the determinants of Knowledge sharing virtual communities. Computers in Human Behavior, pp. 929-939.

Karlsen, J. T., \& Gottschalk, P. (2004). Factors Affecting Knowledge Transfer in IT Projects. Engineering Management Journal.

Kasvi, J., \& Hailikari, M. (2003). Managing Knowledge and Knowledge Competences in Projects and Project Organization. International Journal of Project Management, 21(8).

Kebede, G. (2010). Knowledge management: An information science perspective. International Journal of Information Management, 30, 416-424.

Law, C., \& Ngai, E. (2008). An empirical study of the effect of knowledge sharing and learning on farm performance. Expert system with application, 34, 2342-2349.

Lee, J. N. (2001). The impact of knowledge sharing. Organizational capability and partnership quality on is outsourcing success. Information and Management, 38(5), 5323-5335.

Lindkvist, L. (2004). Governing Project Based Firms: Promoting Market-like Processes With in Hierarchies. Journal of Management and Governance.

Martin, J. (2009). Personal knowledge management: the basic of corporate and institutional knowledgemanagement.

Retrieved

from http://www.Spottedcowpress.ca/knowledgemangement/pdfs/6martinj.pdf, April 2011

Matzler, K. Mooradian, T. A., \& Renzl , B. (2006). Who Trusts? Personality,trust and Knowledge Sharing. Management Learning, 37, 523-540.

McDermott, R., \& O'Dell, C. (2001). Overcoming culture barriers to sharing knowledge. Journal of Knowledge Management, 5(1), 76-85.

Nahapiet, J., \& Ghoshal, S. (1998). Social capital, intellectual capital, and the organizational advantage. Academy of Management Review, 23(2), 242-66.

Politis, J. D. (2001). The relationship of various leadership styles to knowledge management. The Leadership \& Organization Development Jourrnal, 22(8), 354-364.

Renzl, B. (2008). Trust in management and knowledge sharing: The mediating effects of fear and knowledge documentation. Omega, 36, 206-220.

Saucier, G. (1998). Replicable item-cluster subcomponents in the NEO Five-Factor Inventory. Journal of Personality Assessment, 70(2), 263-276.

Singley, M. K., \& Anderson, J. R. (1989). The transfer of cognitive skill (Vol. 9). Harvard University Press.

Spender, J. C. (1996). Making knowledge the basis of a dynamic theory of the firm. Strategic Management Journal, 17, Special Winter issue, pp. 45-62.

Tong, Y., \& Nengmin, W. (2009, July). The Model and Strategy of Knowledge Transfer in Project Enviroments. In Service Science, Management and Engineering, 2009. SSME’ 09. IITA International Conference on (pp. 
120-123). IEEE.

Tseng, S., \& Huang, J. S. (2011). The correlation between Wikipedia and knowledge sharing on job performance. Journal of Expert Systems with Applications, 38, 6118-6124.

Wang, Sh., \& Noe, R. (2010). Knowledge sharing: A review and directions for future research. Human Resource Management Review, 20(2), Publisher: Elsevier In. pp. 115-131.

\section{Copyrights}

Copyright for this article is retained by the author(s), with first publication rights granted to the journal.

This is an open-access article distributed under the terms and conditions of the Creative Commons Attribution license (http://creativecommons.org/licenses/by/3.0/). 